\title{
Smart Industrial Cities Share Services the Full Link Modular APP "iShare" is Designed
}

\author{
Hongyan Xue ${ }^{1}$, Zhengyuan Yang ${ }^{1, *}$, Caifu Jin ${ }^{1}$, Jiali Wang ${ }^{1}$, Xiaoyu Jia ${ }^{1}$, Yunfei Sun ${ }^{2}$ \\ ${ }^{I}$ Zhejiang Normal University, Zhejiang, China \\ ${ }^{2}$ Qingdao University of Science and Technology, Qingdao, China \\ *Corresponding Author.
}

\begin{abstract}
In order to maximize the sharing benefits, this paper designs the smart industrial city modular APP "iShare" based on the thinking of full link, relying on a variety of information technologies and according to the current requirements of smart industrial city construction, and at the background of industrial constructs a new concept and new mode of smart industrial city planning, construction, management and service.
\end{abstract}

Keywords: Smart industrial city, Shared services, the whole link, modular APP

\section{Smart Industrial Cities and the Spirit of Sharing}

\subsection{Smart industrial cities and the spirit of sharing}

With the wave of big data hitting every corner of the world, the construction of smart industrial cities has become a beacon for city administrators to pursue. "City" always revolves around the core elements such as people, environment and information. Cities are developing and upgrading. Smart industrial city construction has now become an important part of China's supply-side structural reform and an important support for sustainable and healthy urban development. The Chinese government defines "smart industrial cities" as "new concepts and models that promote smart urban planning, construction, management and services through the use of next-generation information technologies such as the Internet of Things, cloud computing, big data and spatial and geographic information integration."

Wisdom city as a modern city operation and management of a new model and new concept, based on a comprehensive network communication infrastructure, vast amounts of data resources, many areas such as business process integration, on the basis of informatization and digitization construction, reflects the people-oriented, constructing new wisdom city, people's satisfaction with the "let more information run road, let citizens less running errands" principle, the government service to give full play to the leading role in terms of information. On the basis of policy support and complete infrastructure, the application scenarios of smart industrial city are becoming increasingly rich, such as smart security, smart transportation, smart community, smart business, smart tourism, smart environmental protection, smart energy, etc.

He spirit of sharing is the core of "smart industrial city" construction. The Fifth Plenary Session of the 18th CPC Central Committee put forward the development concept of "innovation, coordination, green, opening up and sharing", among which shared development is the end-result. The five development concepts take sharing as the starting point and foothold of development, specify the value orientation of development, grasp the law of scientific development, and conform to the trend of development of The Times. They are important development concepts that fully reflect the nature of socialism and the purpose of the Communist Party, and scientifically plan for the well-being of the people and the long-term peace and stability of the country. [2]

\section{Sharing Economy and Its Existing Problems}

ISSN: 0010-8189 
The sharing economy developed from the sharing spirit enables people to obtain certain economic benefits while carrying out the sharing idea. Sharing economy emphasizes the right to use rather than the ownership of goods. It is an economic phenomenon in which the public shares idle resources with others through social platforms and then gains considerable income. In recent years, many domestic and foreign enterprises have focused on the investment in smart industrial city and sharing economy. Online short-term rental platform Airbnb and errand-running website TaskRabbit were established in 2008; transportation platform Uber was established in 2009; food sharing website Grubwithus was registered in 2010; In China, shared bicycles, shared umbrellas, shared battery packs, shared space capsules and other shared products were born. At the same time, experts and scholars from all over the world devote themselves to the study of smart industrial city models. In 2006, Howe J proposed the concept of crowdsourcing for the first time, and Wu Chunmao, associate professor of Donghua University, discussed the method of "User Experience Map Model", etc., which provide a scientific social model for the sharing economy of smart cities.

In view of the current development status, the sharing economy of smart cities still has the following problems in the four aspects of "sharing resources", "sharing information", "sharing channels" and "sharing integrity"

Social resources are not really shared, and the sharing of existing physical resources is essentially short-term leasing. For example, a series of products for consumers, such as shared bikes, shared charge banks and shared cars, are owned by companies rather than ordinary users. It is called sharing, in fact, the enterprise rents its products to consumers according to the time, and obtains the income through the rent. The existing social idle resources belonging to individuals are not really used, and even in the period when companies seize market share, a large number of shared products are scrapped and abandoned when they fail to generate sufficient revenue, resulting in a large amount of waste of resources.

Information sharing is not comprehensive, and information release and update cannot be displayed in real time according to the actual situation. Catering, entertainment, travel booking with all kinds of network platform, for example, the user through the network platform to understand the characteristic, catering, entertainment, tourism places information such as price, project, distance and evaluation, but can't get the current time target site traffic saturation, make consumers before to the target site can not be estimated queue and waiting time. From the perspective of merchants, it is enough to attract more business opportunities only by publicizing the store's features and users' favorable comments. However, the lack of real-time dynamic flow data results in consumers wasting a lot of time in waiting, which reduces their satisfaction with leisure and entertainment. Dynamic data display, so that consumers have a more active choice, is also a good choice for rational use of social resources.

Shared channels are not integrated, various information platforms focus on their own advantages, and they have not been seamlessly connected with each other. City is the result of the fusion of many different types of social resources network stack, such as the public transport network, the highway traffic network, represented by park, green land, scenic area of public resource network, with all kinds of food and beverage, amusement parks for leisure entertainment network, even in public toilets, hospitals, supermarkets, represented by public service network. Users living in cities are bound to shuttle back and forth between networks. Integration of information channels and one-stop to meet user needs is the inevitable direction of information sharing channels in the future.

System construction lacks overall planning, data collection lacks standards and norms, credit information lacks substantive application, and working mechanism is not perfect. These problems affect between departments, national, provincial, city and county levels of credit data sharing application, fairness also poses a challenge for credit products, cause huge waste of information resources, especially for severe breach of lack of information sharing will lead to the deterioration of economic transactions, the longer it form vicious circle, is unfavorable to the establishment of good faith society, so to strengthen the public credit information sharing application, effectively break the current domestic government affairs information island, using big data technology enhance the level of comprehensive utilization of credit information and constraint trading main body's credit image, can create a faithless, limitation of credit, So as to improve the construction of sharing spirit of smart industrial city.

ISSN: 0010-8189 


\section{Design of the Full Link Modular APP "Ishare" for Smart Industrial City Sharing Services}

\subsection{Full-link design of shared services}

Full-link design designs every link that users can access in business, and forms an experience circuit by connecting each link, so as to comprehensively improve users' experience in commercial consumption behavior [3]. In the smart industrial city shared service system, the full link design is the inevitable development direction of the service system. Taking short-distance travel as an example, users need to know whether the destination they are interested in is suitable for travel in advance, there are several alternative travel modes and their respective advantages and disadvantages, and when and where they can meet the needs of dining, rest and other needs during the travel process. Existing transportation, recreation, public facilities, respectively belong to different information network system, in the city life is need to log in to a different APP to search information, such as in navigation APP travel routes, looking for the right in the rental car in the car share APP, interested in entertainment APP search restaurant, in the public service APP find nearby supermarket, square, toilet, and so on. From the user's point of view, the full link design enables users to complete the information search in one stop, simplifies the operation steps and improves user satisfaction. From the perspective of each APP itself, the full link design enables each APP to share user information and understand users' consumption and behavior habits through big data analysis, so as to provide more targeted services. Meanwhile, it also improves the wisdom and sharing spirit of the city where it is located.

\subsection{Modular architecture of the service platform}

Using customizable or configurable software modular products to meet customers' increasingly personalized needs for software products is one of the main development directions of software enterprises in the future [4]. Smart industrial city sharing service platform has many functions. Modular architecture can shorten the software design and development cycle, reduce the cost of software products, improve the quality of software products, and facilitate product upgrading. The iShares App module of the service platform is shown in Figure 1

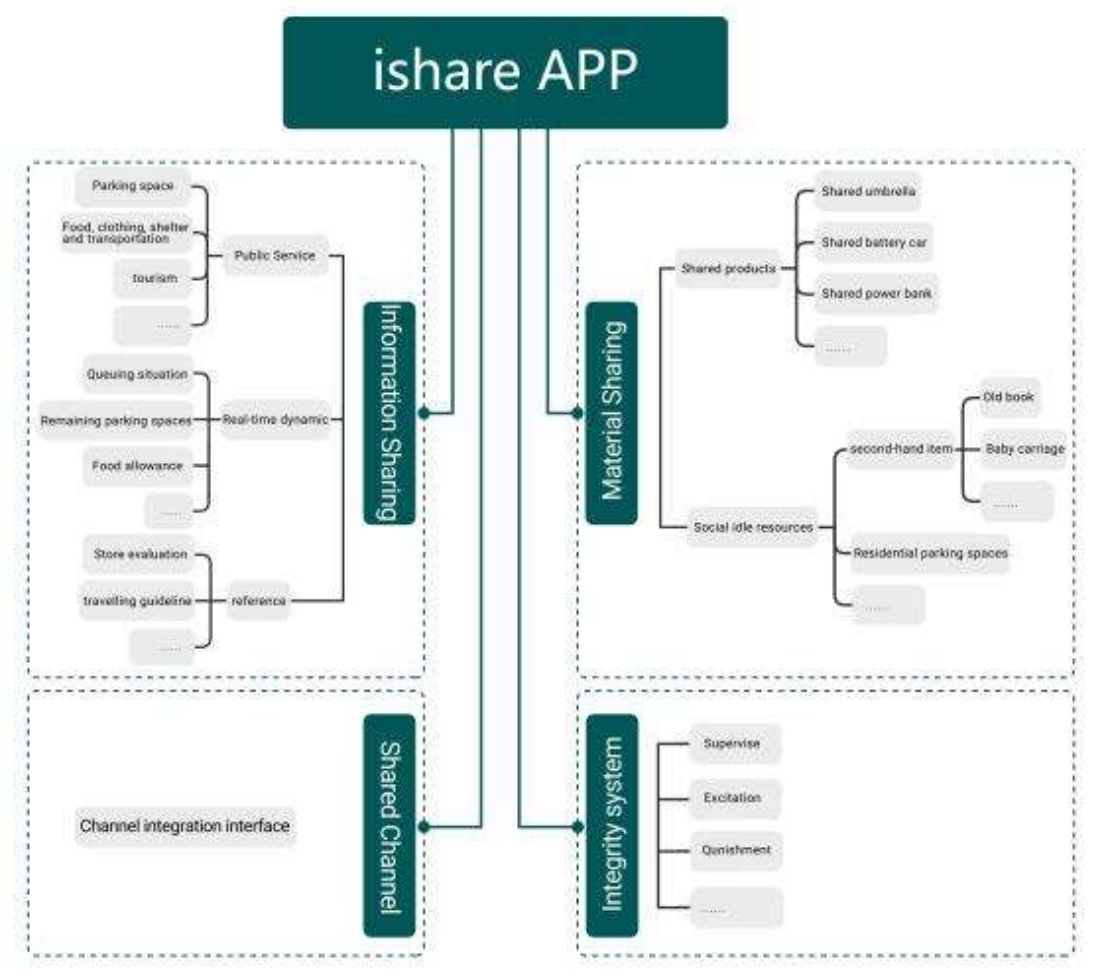


The iShare APP aims to fully share social resources and information. In terms of material sharing, personal resource sharing services should be added on the basis of the existing sharing platform. For example, users can share personal parking Spaces, baby and child supplies on this platform, so as to maximize the utilization of social resources. In terms of information sharing, in addition to the introduction information of the existing leisure and entertainment places and stores, real-time flow heat information is displayed to help consumers screen businesses and avoid the situation of waiting for too long; In terms of sharing channels, channel fusion interfaces should be established for existing platforms, which is convenient for consumers to search for information they need on the one hand, and convenient for data collection and big data analysis for precise docking with demands on the other hand. In terms of the integrity system, it also supervises the integrity behavior of users and businesses to enhance the image of urban civilization and the spirit of sharing. The service system presented by iShare App is shown in Figure 2.

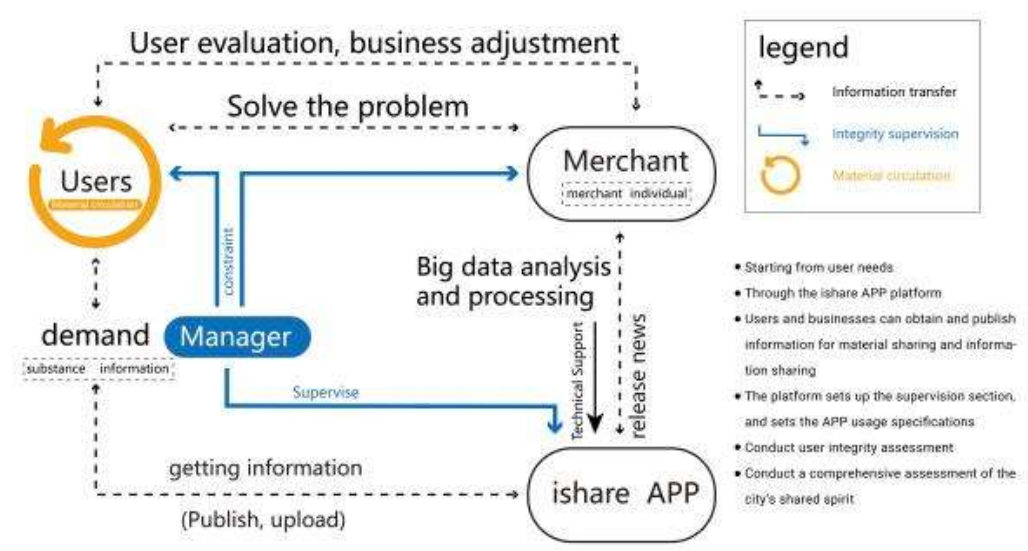

Fig 2: iShare App Service System

The basic information framework of this APP is shown in Figure 3:

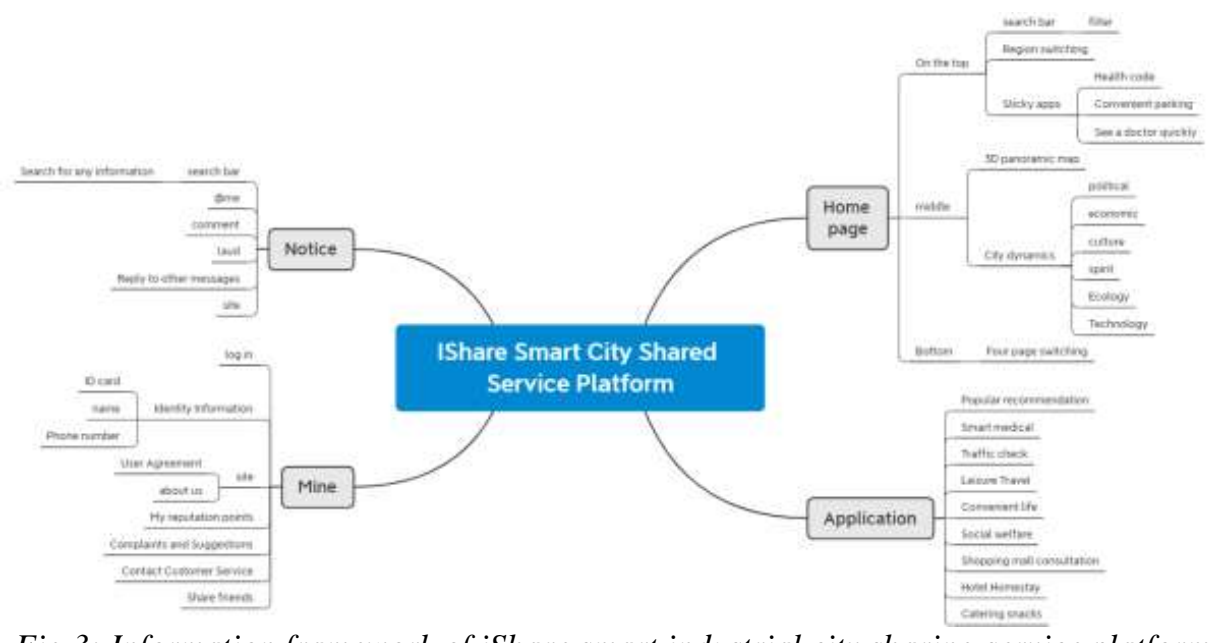

Fig 3: Information framework of iShare smart industrial city sharing service platform

\section{Core Technologies, Innovations and Other Unique Features are Mainly Adopted in This Topic}

4.1 The core technology

Big data analysis. "Big data" brings a new basis for urban research. With the development of information technology,

ISSN: 0010-8189

(C) CONVERTER 2020

www.converter-magazine.info 
big data has penetrated into all fields of global economy and politics, and is changing the way people live, work and think. At the same time, its value has gradually attracted the attention and attention of many scholars in related fields. The rich, detailed and real-time information provided by big data makes the traditional urban space research more comprehensive and detailed. Other technologies rely on it to more accurately explore the internal relations of various Spaces, more accurate than traditional empirical analysis and modeling analysis. Various data acquisition methods, such as mobile phone hotspots, review websites, drone aerial photography, Street View map, etc, provide more channels for data acquisition and bring it into the basic research of other technologies. In this project, the multi-dimensional information collected from users, merchants and public service platforms is obtained through the client, and the data is displayed in the iShareApp platform in a visual way, so that users can make decisions on travel, entertainment, dining and other aspects according to the real-time situation.

2) Application of space syntax [6]. Research on space focuses on the internal abstract structure law of space, so the structure presented is topological structure, which is an abstract object described by topological structure. What it pays attention to is not the actual distance between spatial objects, but its relevance and connectivity. Syntactic refers to the rules that limit the combinatorial relations between multiple Spaces. Its theoretical research is not any independent space segment, but the combinatorial ways of space segments and the relevance among them as the research object. It is a geometric accessibility evaluation method. [7] In this study, space syntax is used to evaluate the accessibility of various existing urban facilities, such as public service facilities, scenic spots, business districts, hospitals, schools, etc., and further explore the geometric accessibility among various facilities, which can effectively evaluate urban construction programs and help guide future urban construction planning. Combined with the attributes and characteristics of various urban facilities, targeted and differentiated design and construction schemes can also be proposed to help each urban facility find a unique development path.

3) Application of Kano Model [8]. Kano Model is an analysis tool for classifying and prioritizing user needs. Based on the analysis of the impact on user needs and user satisfaction, it shows the nonlinear relationship between product functional factors and user satisfaction, and realizes the structured analysis of user psychology [9]. Through the Kano model, the product can better fit the business needs. From the two dimensions of the degree of availability and satisfaction, the basic functions and value-added functions in the product can be defined, and how to arrange the priority of various functions in the product. In this topic, the Kano model is used to analyze the user needs of the smart industrial city shared service system, clarify the service demands, service elements and service quality, and improve the service scope and specification of the shared service system.

4) $3 \mathrm{D}$ panoramic model [10] was established. Is a kind of $3 \mathrm{~d}$ panoramic model on surrounding scenery or things in a certain geometry associated plan into a panoramic view of refraction, the show is the omni-directional three-dimensional images of real sense of reality, the whole domain, and has a strong sense of interaction, which shows the intuitive visual impact, brings the user immersive experience, highly efficient participatory and interactive. The 3D panoramic model is used to help users search target roads and buildings more intuitionally, construct spatial orientation and improve user satisfaction.

4.2 The innovation points contained in this topic mainly lie in:

1) Through the platform, the idle resources will be utilized to the maximum extent, and the sharing scope will be expanded from individual sharing to social sharing.

2) Real-time display of merchant flow number, giving users more initiative to choose;

3) Integration of various sharing channels, one-stop to meet user information search and travel strategy needs;

4) Through the trip data, the integrity of merchants, platforms and users can be recorded permanently in real time.

4.3 The uniqueness of this topic lies in:

ISSN: 0010-8189

(C) CONVERTER 2020

www.converter-magazine.info 
1) Multi-technology application: Big data analysis, space syntax, Kano model and 3D panoramic city model are applied to improve the spirit index of city sharing;

2) Timeliness: the service content of the sharing platform turns from mass to private customization and individuation.

3) Times: lead a new way of life, break the status quo of social difficulties, develop cloud social, promote the all-round development of smart industrial city.

\section{Conclusion}

The construction of a smart industrial city based on shared services is conducive to promoting the overall modernization of society and enhancing the competitiveness of cities. The construction goal of smart industrial city is to achieve fine urban management, livable living environment, and long-term network security. The current data of hangzhou city, zhejiang province, for example, the brain is to use cutting-edge technology to deal with the data, in order to realize the multiple platforms, to participate in social management system and application of artificial intelligence center, but it still has some defects, such as the user to use temporary, real-time, connectivity, sudden, variability, whole mergence, regulatory aspects is the short board, this paper puts forward the whole link modular APP "(" is to solve the above problem, make wisdom city Shared services more personalized, diversified and precision. Any city can embed the APP "iShare" module into its smart industrial city construction with shared services as the core according to its own cultural and economic conditions. "IShare" is a scientific social model of intelligent city sharing service construction with Hell characteristics.

\section{References}

[1] "Guiding Opinions on Promoting Healthy Development of Smart Cities," August 27, 2014.

[2] J. W. Liang, "The conception and significance of shared development concept," Guangdong Economy, July 8, 2019.

[3] J. Zhang, S. Chen, "Research on innovative design of unmanned store based on full link user experience path," Packaging Engineering, vol. 40, no. 04, pp. 21-29, 2019.

[4] M. Z. Xia, Y. X. Xia, B. Y. Li, "Software modular design and modular management," China Information Industry, no. 11, pp. 56-59, 2012.

[5] J. W. He, "Design of tourism intelligent platform based on big data analysis technology," Modern Electronic Technology, vol. 43, no. 14, pp. 183-186, 2020.

[6] Y. F. Fu, Y. Fang, Z. Y. Bao, "Research on accessibility of comprehensive parks in Hangzhou based on spatial syntax and LBS big data," Landscape Architecture, vol. 8, no. 02, pp. 69-75.

[7] X. W. Ma, H. Y. Xue, "Intelligent smart industrial city parking facility layout optimization based on intelligent IOT analysis," Computer Communication, vol. 153, no. 1, pp. 145-155, 2020

[8] N. Kano, N. Se Raku, F. Takahashi, et al., "Attractive quality and must-be quality," The Journal of Japanese Society for Quality Control, vol. 4, no. 2, pp. 39-48, 1984.

[9] M. Yi, J. Z. Song, Z. Q. Li, "Research on functional requirements of university intelligent library based on Kano model," Library and Information Service, vol. 64, no. 14, pp. 45-53, 2020.

[10] Z. Liu, C. Y. Zhan, D. Huang, "Vehicle 3D panoramic model and texture mapping algorithm," Computer Engineering and Design, vol. 38, no. 01, pp. 172-176, 2017. 